This item was submitted to Loughborough's Research Repository by the author.

Items in Figshare are protected by copyright, with all rights reserved, unless otherwise indicated.

\title{
Anti-buoyancy and unidirectional gas evolution by Janus electrodes with asymmetric wettability
}

PLEASE CITE THE PUBLISHED VERSION

https://doi.org/10.1021/acsami.0c04796

\section{PUBLISHER}

American Chemical Society (ACS)

\section{VERSION}

AM (Accepted Manuscript)

\section{PUBLISHER STATEMENT}

This document is the Accepted Manuscript version of a Published Work that appeared in final form in ACS Applied Materials \& Interfaces, copyright $@$ American Chemical Society after peer review and technical editing by the publisher. To access the final edited and published work see https://doi.org/10.1021/acsami.0c04796

\section{LICENCE}

CC BY-NC-ND 4.0

\section{REPOSITORY RECORD}

Sheng, Siyu, Bairu Shi, Cheng Wang, Liang Luo, Xiao Lin, Pengsong Li, Fanhong Chen, et al.. 2020. "Antibuoyancy and Unidirectional Gas Evolution by Janus Electrodes with Asymmetric Wettability”. Loughborough University. https://hdl.handle.net/2134/12246113.v1. 


\section{ACS APPLIED MATERIA Len Loughborough \&INTERFAC University}

Surfaces, Interfaces, and Applications

\section{Anti-buoyancy and Unidirectional Gas Evolution by Janus Electrodes with Asymmetric Wettability}

Siyu Sheng, Bairu Shi, Cheng Wang, Liang Luo, Xiao Lin, Pengsong Li, Fanhong

Chen, Zhicheng Shang, Hong Meng, Yun Kuang, Wen-Feng Lin, and Xiaoming Sun

ACS Appl. Mater. Interfaces, Just Accepted Manuscript • Publication Date (Web): 29 Apr 2020

Downloaded from pubs.acs.org on May 2, 2020

\section{Just Accepted}

"Just Accepted" manuscripts have been peer-reviewed and accepted for publication. They are posted online prior to technical editing, formatting for publication and author proofing. The American Chemical Society provides "Just Accepted" as a service to the research community to expedite the dissemination of scientific material as soon as possible after acceptance. "Just Accepted" manuscripts appear in full in PDF format accompanied by an HTML abstract. "Just Accepted" manuscripts have been fully peer reviewed, but should not be considered the official version of record. They are citable by the Digital Object Identifier (DOI®). "Just Accepted" is an optional service offered to authors. Therefore, the "Just Accepted" Web site may not include all articles that will be published in the journal. After a manuscript is technically edited and formatted, it will be removed from the "Just Accepted" Web site and published as an ASAP article. Note that technical editing may introduce minor changes to the manuscript text and/or graphics which could affect content, and all legal disclaimers and ethical guidelines that apply to the journal pertain. ACS cannot be held responsible for errors or consequences arising from the use of information contained in these "Just Accepted" manuscripts. 


\title{
Anti-buoyancy and Unidirectional Gas Evolution by Janus Electrodes with Asymmetric Wettability
}

\author{
Siyu Sheng ${ }^{\dagger}$, Bairu Shi ${ }^{\S}$, Cheng Wang*, Liang Luo ${ }^{\dagger *}$, Xiao Lin", Pengsong L $i^{\dagger}$, \\ Fanhong Chen ${ }^{\dagger}$, Zhicheng Shang ${ }^{\dagger}$, Hong Meng ${ }^{\dagger}$, Yun Kuang ${ }^{\dagger}$,Wen-Feng Lin ${ }^{\perp *}$ and \\ Xiaoming Sun ${ }^{\dagger *}$
}

$\dagger$ State Key Laboratory of Chemical Resource Engineering, Beijing Advanced Innovation Centre for Soft Matter Science and Engineering, Beijing University of Chemical Technology, Beijing 100029, China

$\S$ Research Institute of Petroleum Exploration and Development, Beijing 100083, China

$\ddagger$ Chinese Research Academy of Environmental Sciences, Beijing 100012, China

\| Department of Chemical Engineering and Biotechnology, University of Cambridge, Cambridge, CB3 0AS, UK

$\perp$ Department of Chemical Engineering, Loughborough University, Loughborough, Leicestershire, LE11 3TU, UK

*Corresponding author: luoliang@mail.buct.edu.cn, w.lin@lboro.ac.uk, sunxm@mail.buct.edu.cn

\begin{abstract}
The bubbles electrochemically generated by gas evolution reactions are commonly driven off the electrode by buoyancy, a weak force used to overcome bubble adhesion barriers, leading to low gas transporting efficiency. Herein, a Janus electrode with asymmetric wettability has been prepared by modifying two sides of a porous stainless-steel mesh electrode, with superhydrophobic polytetrafluoroethylene (PTFE) and $\mathrm{Pt} / \mathrm{C}$ (or Ir/C) catalyst with well-balanced hydrophobicity, respectively; affording unidirectional transportation of as-formed gaseous hydrogen and oxygen from the catalyst side to the gas-collecting side during water splitting. "Bubble-free" electrolysis was realized when "floating" the Janus electrode on the electrolyte. Anti-buoyancy through-mesh bubble transportation was observed when immersing the electrode with PTFE side downward. The wettability gradient within the electrode endowed sticky states of bubbles on the catalyst side, resulting in efficient "bubble-free" gas transportation with 15 folds higher current density than submerged states.
\end{abstract}

Keywords : anti-buoyancy, unidirectional, Janus electrode, gas evolution reaction, bubble-free, sticky-state 


\section{Introduction}

Gas involving electrochemical reactions are of great significance in energy storage and conversion, such as water splitting, fuel cells and rechargeable metal-air batteries. ${ }^{1,2}$ Over the past two decades, tremendous research efforts have been devoted to developing highly active catalysts. ${ }^{3-10}$ Yet, gas-liquid-solid multiphase mass transfer has also been demonstrated to be critical for the performance improvement. ${ }^{11,12}$ For gas evolution reactions, if the generated bubbles cannot detach from the electrode surface in time, they would accumulate to cover the electrode surface, ${ }^{3}$ block the electrode/electrolyte contact, reduce catalytic active sites, and thus lead to high diffusion resistance and severe efficiency loss. ${ }^{13,14}$

To overcome this limitation, superaerophobic electrodes, which have been proposed to decrease the adhesion force of as-formed bubbles, are widely used in gas evolution reactions including hydrogen evolution reaction (HER), oxygen evolution reaction (OER), hydrazine oxidation reaction $(\mathrm{HzOR})$ and chlorine evolution reaction (ClER). ${ }^{15,16}$ Generally, the behaviors of as-formed bubble and consequent mass transportation at the three phase boundaries are governed by the gravity (i.e., buoyancy). Large-scale industrial gas production devices such as electrolysers would require unidirectional transportation of gases, which sometimes need antigravity diffusion. Resistance-free transportation would be challenging and highly appealing but with limited progress. ${ }^{17}$ In other cases, micro- or zero-gravity environments (i.e., almost no buoyancy) might lead to heavily bubble-sticking on the electrodes, causing severe loss of active sites and sluggish gas transportation. ${ }^{18}$

Recently, gradient wetting materials, ${ }^{19-25}$ which could capture and transport liquids and gases along the wettability gradient, have been used in water harvesting, ${ }^{26}$ oil/water separation, ${ }^{27-29}$ and biological enzyme catalytic reaction. ${ }^{30-32}$ It is generally accepted that the driving force for unidirectional transportation essentially arises from the wettability gradient, ${ }^{26,33}$ which provides continuous concentration differences along the gradient, i.e., the concentration gradient. As these liquid/gas harvesting processes only involve diffusions and do not have high resistances, the generated concentration gradient could drive the unidirectional transportation. However, as different from the liquid/gas harvesting processes, electrocatalytic gas evolution reactions occur on the electrode in the electrolyte. Bubble sticking on the electrode requires higher driving force to release the generated gases. Usually the bubbles are driven off the electrode by buoyancy, a weak force used to overcome bubble adhesion barriers, leading to sluggish bubble releasing behavior. Designing advanced electrode structures that have a sufficient intrinsic driving force to overcome the energy barrier of unidirectional transportation is in high demand, yet remains a challenge.

In this study, a Janus electrode with asymmetric wettability was proposed and fabricated to serve as the efficient working electrode for anti-buoyancy and unidirectional bubble transportation in water splitting reaction. The Janus electrode was prepared by employing hydrophobic PTFE on one side of the porous 
stainless-steel mesh electrode (aerophilic side, AI in brief), followed by coating commercial $\mathrm{Pt} / \mathrm{C}$ or $\mathrm{Ir} / \mathrm{C}$ catalyst on the other side of the mesh (aerophobic side, AO in brief). The $\mathrm{Pt} / \mathrm{C}$ or $\mathrm{Ir} / \mathrm{C}$ side worked as a catalyst for HER or OER, with well-balanced wettability to make it highly sticky to the pinned bubbles ${ }^{27}$. The unidirectional or even anti-buoyancy transportation of bubbles was observed when the Janus mesh electrode was placed vertically or horizontally with PTFE side downward. When floating the Janus electrode over the electrolyte surface with the aerophilic PTFE side facing the gas environment while the aerophobic $\mathrm{Pt} / \mathrm{C}$ catalyst side facing the electrolyte respectively, the generated $\mathrm{H}_{2}$ gas could be directly transported to the gas phase to realize bubble-free electrolysis. The "bubble-free" behavior endowed a 15 -folds higher current than that working in traditional submerged state.

\section{Experimental Section Materials}

All reagents used were commercially available, with analytical grade and without further purification. Polytetrafluoroethylene (PTFE) was obtained from Aladdin Chemical Reagent Co. Pt/C catalyst was obtained from Alfa Aesar Corporation. Ir/C catalyst was obtained from Macklin Corporation. $\mathrm{H}_{2} \mathrm{PtCl}_{6} \cdot 6 \mathrm{H}_{2} \mathrm{O}$ and $\mathrm{KNO}_{3}$ were obtained from Sinopharm Co., Other materials, such as $\mathrm{H}_{2} \mathrm{SO}_{4}(\approx 98 \mathrm{wt} \%), \mathrm{HCl}(\approx 38$ wt $\%)$, and $\mathrm{CH}_{3} \mathrm{CH}_{2} \mathrm{OH}(\approx 99.7 \mathrm{wt} \%)$ were all of A.R. grade, purchased from Beijing Chemical Reagent Co., and used as received.

\section{Preparation of Janus mesh electrode with an asymmetric wettability}

Stainless steel mesh was cleaned with hydrochloric acid, distilled water, then ethanol with ultrasonication, and dried at $60{ }^{\circ} \mathrm{C}$. PTFE solution was sprayed to one side of the mesh from a distance of $20 \mathrm{~cm}$, and the electrode was dried under the infrared lamp. The spray and drying were repeated for three times. During the drying, the PTFE solution could be naturally infiltrated into the mesh channel by capillary forces and formed a wettability gradient. Then the mesh was annealed at $350{ }^{\circ} \mathrm{C}$ for 30 min with argon atmosphere.

Then Pt/C catalyst was applied on the other side of the mesh unsprayed by PTFE for HER test. The $\mathrm{Pt} / \mathrm{C}$ catalyst film was fabricated by drop-casting method. Specifically, the $\mathrm{Pt} / \mathrm{C}$ catalyst $(20 \mathrm{wt} \% \mathrm{Pt})$ was dispersed in ethanol with a concentration of $1 \mathrm{mg} / \mathrm{mL}$. Then $1 \mathrm{~mL} \mathrm{Pt/C}$ suspension was uniformly dropped to one side of the mesh $(1 \times 1 \mathrm{~cm})$ with a pipette, and repeated for several times after each drying until the $\mathrm{Pt} / \mathrm{C}$ suspension was used out. The $\mathrm{Ir} / \mathrm{C}$ catalyst was selected for the OER test with similar procedures as the $\mathrm{Pt} / \mathrm{C}$ for the HER test.

Janus Pt Flower and Pt Island coated mesh electrodes were fabricated via electroplating method employing stainless mesh substrates $(1 \mathrm{~cm} \times 1 \mathrm{~cm})$. A carbon rod was used as counter electrode and an $\mathrm{Ag} / \mathrm{AgCl}$ electrode was used as reference electrode. The $\mathrm{Pt}$ Flower coated mesh was prepared by potentiostatic electrodeposition with the deposition potential up to $-0.30 \mathrm{~V}$, while Pt island coated mesh was electroplated via cyclic electrodeposition with potential controlled in a range from -0.2 to $0.5 \mathrm{~V}$ at a scan rate $0.01 \mathrm{~V} \mathrm{~s}^{-1}$ for 15 cycles. $\mathrm{H}_{2} \mathrm{PtCl}_{6}\left(3 \times 10^{-3} \mathrm{M}\right)$ 
solution with $\mathrm{KNO}_{3}\left(100 \times 10^{-3} \mathrm{M}\right)$ was employed as electrolyte in both of the electrodeposition processes. Both electrodes were deposited on only one side of the mesh by covering PTFE side with tape.

\section{Characterization}

The morphologies of samples were characterized using a field-emission SEM (Zeiss SUPRA 55) operating at $20 \mathrm{kV}$. The electrochemical measurements were carried out at room temperature in a standard three-electrode glass cell connected to an electrochemical workstation (CHI 660D, Chenhua, Shanghai). $\mathrm{Ag} / \mathrm{AgCl}$ electrode was used as reference electrode and a carbon rod was used as the counter electrode. All electrochemical tests were measured in $0.5 \mathrm{M} \mathrm{H}_{2} \mathrm{SO}_{4}$. The liquid droplet and bubble underwater contact angles were measured using a contact angle system (OCA 21, Dataphysics, Germany) at room temperature, with the probe liquid ( $2 \mu \mathrm{L})$ and oxygen bubble $(2 \mu \mathrm{L})$. The adhesive forces between the $\mathrm{H}_{2}$ bubbles and electrode interfaces can be assessed by a high-sensitivity micro-electromechanical balance system (Dataphysics DCAT11, Germany).

\section{Results and discussion}
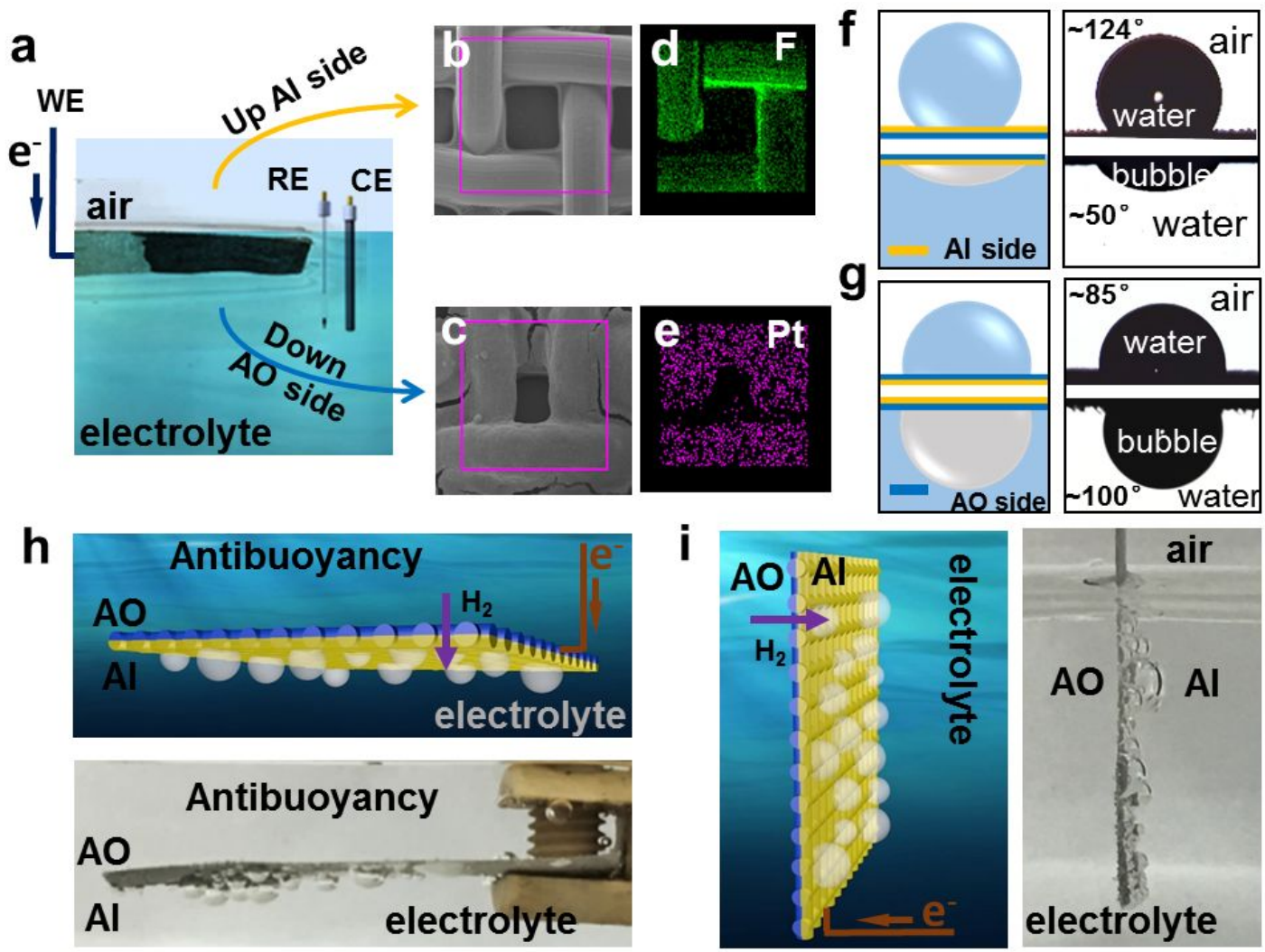

Figure 1. (a) Digital camera image of Janus electrode floating over the electrolyte with the aerophilic (AI) side upward and aerophobic (AO) side downward during hydrogen evolution reaction. WE: Janus mesh electrode, CE: carbon rod, RE: $\mathrm{Ag} / \mathrm{AgCl}$ electrode. SEM images of (b) aerophilic and (c) aerophobic side and elemental mapping images of (d) F and (e) Pt. (f, g) Digital camera images showing 
different wettabilities of the two sides of the Janus electrode. (h, i) Digital camera image and schematic illustration of Janus electrode (h) submerged in the electrolyte with AI side downward and AO side upward and (i) submerged vertically in the electrolyte.

Fabrication of Janus electrode is illustrated in Figure 1a. The stainless-steel mesh electrode substrate was modified by PTFE as the aerophilic (AI) side, followed by coating $\mathrm{Pt} / \mathrm{C}$ catalyst on the other side as the aerophobic (AO) part. HER was investigated as the model reaction with the Janus mesh electrode as the working electrode, $\mathrm{Ag} / \mathrm{AgCl}$ electrode as the reference electrode, and a carbon rod as the counter electrode. As revealed by the SEM images (Figure 1b and 1c) and elemental mapping (Figure 1d and 1e) of the two sides of the Janus working electrode, $\mathrm{Pt} / \mathrm{C}$ and PTFE were uniformly coated on the two sides of the electrode, respectively. The contact angles (CA) of a water droplet and a gas bubble on the PTFE side were $124^{\circ} \pm$ $1.2^{\circ}$ and $50^{\circ} \pm 2.3^{\circ}$, respectively (Figure $1 \mathrm{f}$ ). While for the $\mathrm{Pt} / \mathrm{C}$ surface, the CA were $85^{\circ} \pm 1.7^{\circ}$ and $100^{\circ} \pm 3.5^{\circ}$, respectively (Figure $1 \mathrm{~g}$ ), indicating the asymmetric wettability of the Janus electrode after PTFE and catalyst coating on the two sides. By placing the Janus electrode with AI surface upward and AO surface downward over the electrolyte, the generated $\mathrm{H}_{2}$ could be unidirectionally transported through the tunnels of the mesh electrode into the gas phase directly, with no apparent bubbles observed on the AO surface (Figure 1a) to realize "bubble-free" electrolysis. To further evaluate the gas diffusion properties, the Janus mesh electrode was submerged into the electrolyte with AO side upward and AI side downward (Figure 1h). In another case, it was vertically placed (Figure 1i) in the electrolyte solution. The bubbles always transported through the tunnels, from AO side to AI side, for both cases. It even overcame the buoyancy (Figure 1h) in former case, indicating the strong driving force of unidirectional gas transportation. 

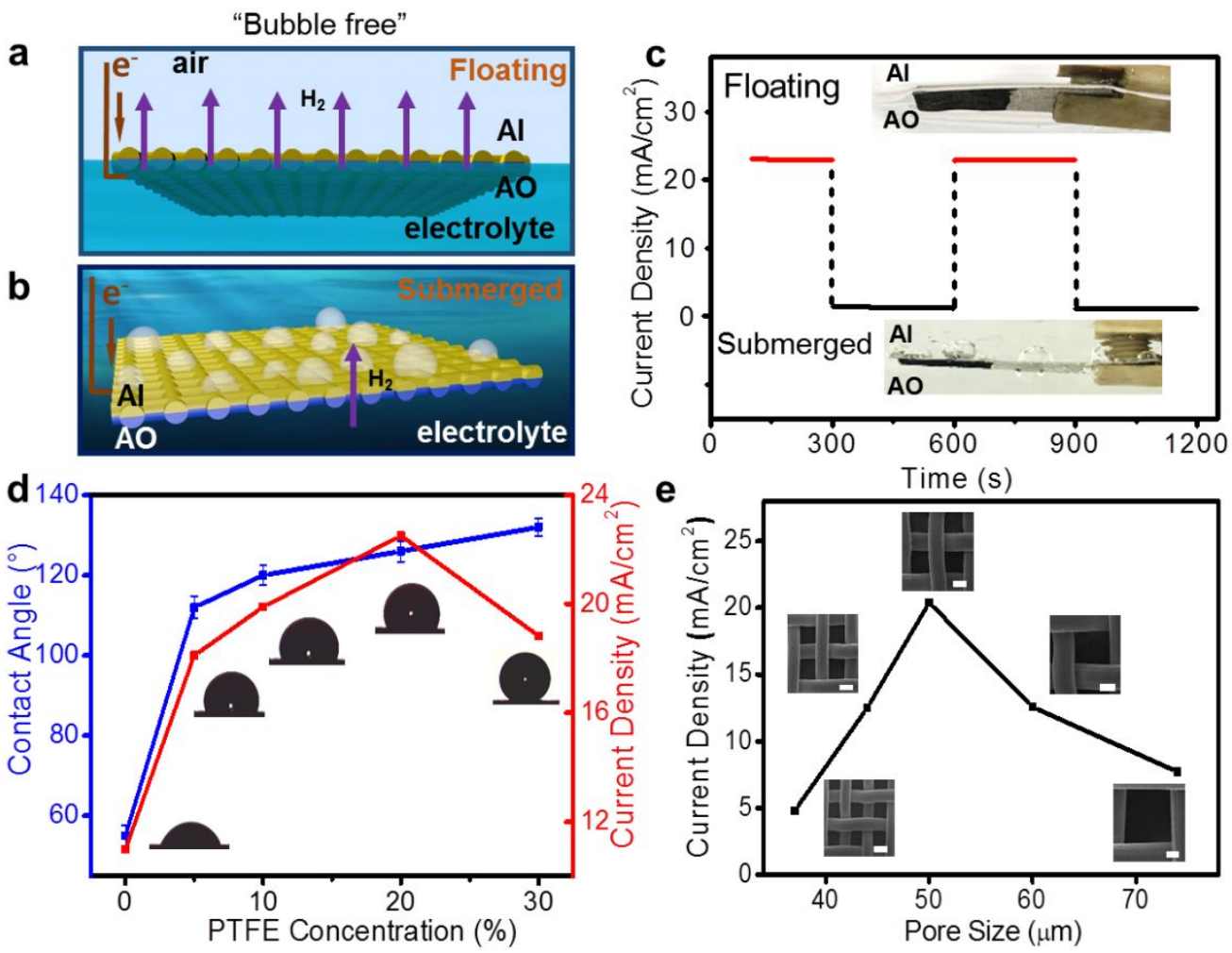

Figure 2. (a-b) Schematic illustration and (c) comparison of current densities for Janus electrode with floating or submerged states. (d) Different water contact angles and current densities of the AI side of Janus electrodes modified with different PTFE concentration. (e) Current densities of Janus electrodes with different pore sizes, scale bars are $20 \mu \mathrm{m}$.

Such efficient unidirectional gas transportation effect allows the generated $\mathrm{H}_{2}$ gas to depart from the active sites timely, leading to boosted reaction kinetics. This was evidenced by the control experiments of floating the Janus electrode over electrolyte and submerging into the electrolyte, respectively. As demonstrated in Figure 2a-c, when the electrode was floating on the electrolyte (bubble-free electrolysis), the current density was 15 -folds higher than that of the submerged state (even not anti-bouncy). In the submerged situation, the gas transportation through the tunnels has to overcome higher hydrostatic pressure, and the bubbles will be formed on the catalyst side and inevitably block active sites at a certain extent (Figure 2a). We further investigated the influence of aerophilicity of AI surface and the pore size of mesh electrode on the performance. The mesh electrodes with PTFE modification $\left(22.51 \pm 2.3 \mathrm{~mA} \mathrm{~cm}^{-2}\right)$ exhibited much higher current density than that without PTFE modification (12.5 $\pm 5.5 \mathrm{~mA} \mathrm{~cm}^{-2}$ ) (Figure $2 \mathrm{~d}$ and Figure S1, Supporting Information). As the concentration of PTFE coating solution increased from $5 \%$ to $20 \%$, the hydrophobicity increased and the water CA of AI surface increased from $55^{\circ} \pm 2.7^{\circ}$ to $120^{\circ} \pm 2.3^{\circ}$, along with a corresponding current density increase, which reached the maximum value of $23 \pm 2.5 \mathrm{~mA} \mathrm{~cm}^{-2}$. As the thickness of AI layer increased and the water column height in the pores would be reduced and easy for gas transport. 
However, when the concentration of PTFE coating solution was further increased to $30 \%$, the current density decreased though the contact angle still increased from $126^{\circ} \pm 2.5^{\circ}$ to $132^{\circ} \pm 2.3^{\circ}$. This is caused by the fact that the overmodified hydrophobicity in the tunnels of the mesh would cause a serious capillary effect and block the contact between the active sites and the electrolyte. For the pore size effect, we have tried AAO membranes with various nanopores as the current collector, but most of the as-generated bubbles could hardly transport through the AAO membrane owing to the rather small pore size (Figure S2). It suggested that based on the nanopore electrodes, the gas transport rate cannot match the gas generation rate. As a result, we selected stainless steel mesh with micron pore size and $10 \mu \mathrm{m}$ in thickness as the Janus substrate (Figure 2e). As the average pore size of the mesh increased from $37 \mu \mathrm{m}$ to $50 \mu \mathrm{m}$, the current density increased from $4.8 \mathrm{~mA} \mathrm{~cm}^{-2}$ to $22.4 \mathrm{~mA}$ $\mathrm{cm}^{-2}$. It is understandable that the transportation of generated bubbles happened slowly with the small pore sized mesh, mainly due to the limited tunnels for gas transportation. As increasing the pore size, the gas transportation would become much easier, preventing bubbles blocking the active sites. While when the pore size continuously increased to $74 \mu \mathrm{m}$, the efficient unit active area was significantly reduced, resulting in a decrease of current density to $7.7 \mathrm{~mA} \mathrm{~cm}^{-2}$. Thus, the balance between pore size and effective active area should be carefully considered.
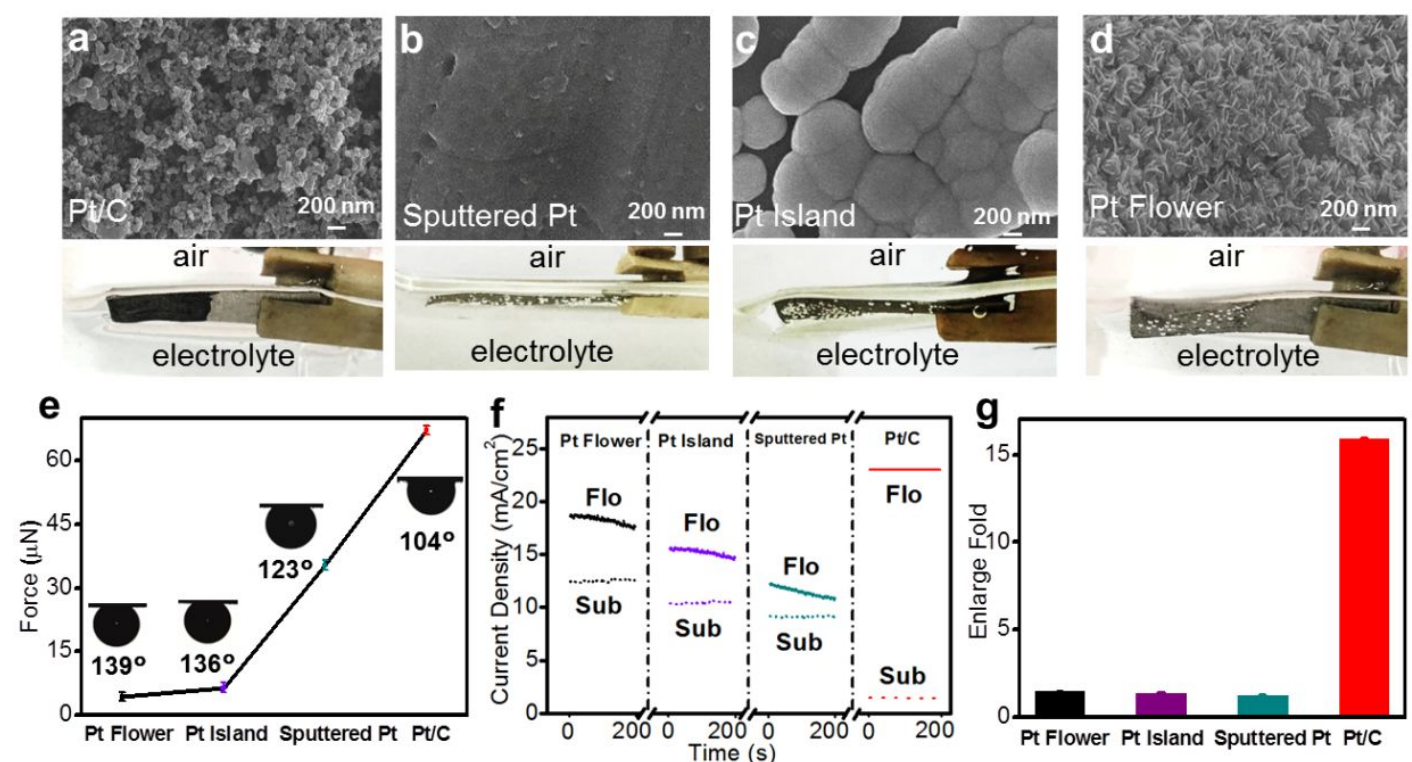

Figure 3. (a-d) SEM images and camera images of Janus electrode coated with four different catalysts: Pt/C nanoparticles, sputtered Pt film, Pt island and Pt flower array. (e) Adhesive force measurement on the above four catalysts with different bubble contact angles. (f) HER current densities obtained on different Pt catalysts at a constant potential of $-0.30 \mathrm{~V}$ vs RHE.(Flo: Floating state. Sub: Submerged state) (g) The current density enhancement factors on the four different catalyst surfaces.

However, for the AO side, it is noted that the superaerophobic catalyst (Pt flower), which was considered as a good candidate, but failed to top the performance. This 
was beyond our expectation as superaerophobic electrodes usually show good gas evolution behavior due to fast gas bubble releasing. In order to further explore the influence of wettability on the HER performance of the Janus electrodes, four kinds of $\mathrm{Pt}$ catalysts (Pt/C nanoparticles, sputtered $\mathrm{Pt}$ film, microsized $\mathrm{Pt}$ islands and $\mathrm{Pt}$ flower arrays) with different morphologies and wetabilities were employed, as shown in Figure 3a-d. Different morphologies lead to different gas bubble contact angles, i.e., $104^{\circ} \pm 3.2^{\circ}, 123^{\circ} \pm 2.6^{\circ}, 136^{\circ} \pm 1.3^{\circ}$ and $139^{\circ} \pm 1.2^{\circ}$ for $\mathrm{Pt} / \mathrm{C}$ nanoparticles, sputtered $\mathrm{Pt}$ film, microsized Pt islands and Pt flower arrays, respectively (Figure 3e, inset), while the adhesive forces were $67.3 \mu \mathrm{N}, 35.3 \mu \mathrm{N}, 6.4 \mu \mathrm{N}$ and $4.2 \mu \mathrm{N}$, respectively (Figure 3e and Figure S3-4, Supporting Information). It is noted that the carbon supported Pt $(\mathrm{Pt} / \mathrm{C})$ was not as hydrophilic as Pt metal, inducing less aerophilicity than other three Pt surfaces studied. With different wettabilities on the AO side but the same wettability on the AI side, the gas transportation behaviors of the four Janus electrodes studied were obviously different. Bubble free electrolysis only happened on the Janus electrode with $\mathrm{Pt} / \mathrm{C}$ catalyst on the $\mathrm{AO}$ side, where the generated $\mathrm{H}_{2}$ could be totally unidirectionally transferred to the AI side and then released to the air, while there were always bubbles adhered on the other three electrodes. As a result, the $\mathrm{Pt} / \mathrm{C}$ based Janus electrode showed the most obvious performance improvement when switched from the submerged state to the floating state (Figure $3 \mathrm{f}$ and $3 \mathrm{~g}$ ). HER polarization curves also showed a higher performance of $\mathrm{Pt} / \mathrm{C}$ based electrode than the other three kinds of Janus electrodes (Figure S5, Supporting Information). The HER Faraday efficiency under floating condition could reach to higher than $96 \%$. The generated bubble penetration efficiency of the Janus electrode was calculated to be $0.17 \mathrm{~mL} / \mathrm{cm}^{2} \cdot \min$ according to the gas chromatography result, and that of each pore was about $1.9 \times 10^{-3} \mu \mathrm{L} / \mathrm{min}$. Similar trend was found on the oxygen evolution reaction (OER) at the anode side that the $\mathrm{Ir} / \mathrm{C}$ based Janus mesh electrode exhibited the best OER performance as well as the most efficient gas transportation (Figure S6-7, Supporting Information). 

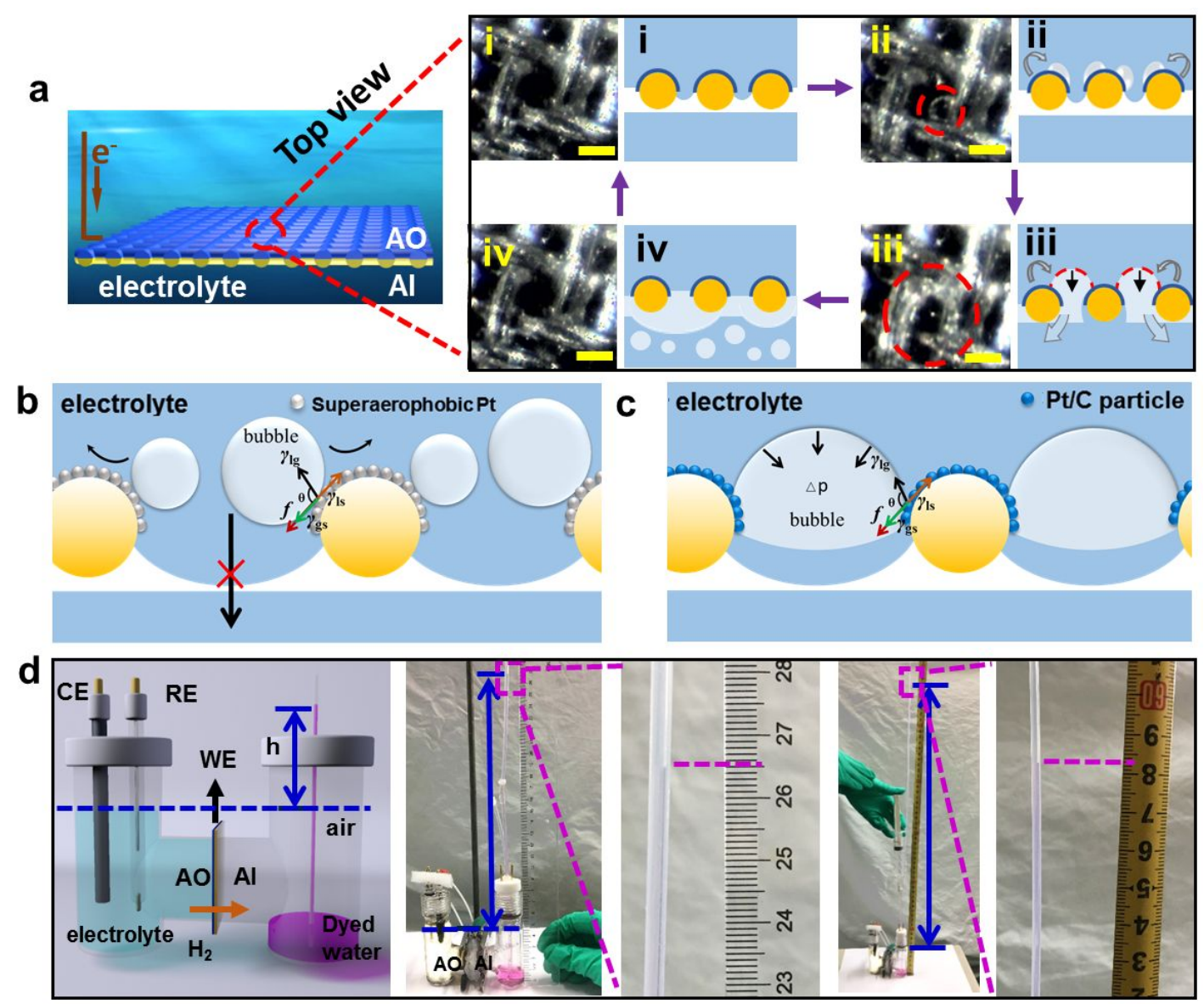

Figure 4. (a) Magnified snapshots and illustration of a bubble evolution cycle on the $\mathrm{Pt} / \mathrm{C}$ catalyst side (i.e., the AO side). Scale bars are $50 \mu \mathrm{m}$. Analysis of bubble transportation on (b) plain aerophobic surface and (c) sticky aerophobic surface. (d) Measurement of generated vapor pressure based on the Janus electrode.

The efficient transfer behavior was further investigated via high speed photography. On the $\mathrm{Pt} / \mathrm{C}$ surface, there were many bright spots (Figure S8, Supporting Information) periodically blinking under working conditions, rather than forming intact bubbles. Magnified images of a single tunnel (AO side) showed that the generated gas accumulated to form microbubbles which pinned on the edge of mesh frame and gradually expanded to a spherical cap and eventually released (Figure 4a). The whole cycle includes four steps: 1) The generated gas molecules accumulated on the catalyst surface and form small bubbles on the mesh frames (Figure 4a i-ii). 2) Due to the appropriate wettability, the steady pinning of small bubbles on TPCL(three-phase contact line) at the $\mathrm{Pt} / \mathrm{C}$ side (AO side) guaranteed an increase of bubble pressure, and small bubbles fused to form bigger cap like bubbles pinned between the mesh frames (Figure 4a ii-iii). 3) The bubble pressure was finally released via the de-pinning of the contact line on the aerophilic side of mesh by overcoming the hydrodynamic repulsion of the electrolyte inside the tunnels of the mesh, which was similar to a "stick-slip" motion ${ }^{34}$ for bubble motion inside the Janus mesh (Figure 4a iii-iv). 4) After penetration of most gas bubbles, generation of small 
bubbles would start over again (Figure $4 \mathrm{a}$ iv-i). While for the other three surfaces (Pt film, Pt island and Pt flower array), bubbles would keep growing up continuously on the frame followed by de-pinning of TPCL on the frame, while no cap like bubbles pinned between the mesh frames was formed (Figure S8, Supporting Information).

As the appropriate wettability endows the unique sticky state of the cap like bubbles, the force analysis was conducted (Figure S9, Supporting Information). The bubble is affected by lateral resistance and the effect of surface tension, ${ }^{35,36}$ and the change of contact angle is equivalent to the advancing contact angle according to Young's equation. ${ }^{37}$ Thus, the lateral resistance $(f)$ can be expressed as, ${ }^{38}$

$$
f=\frac{1}{2} \gamma_{l g}\left(\cos \theta_{r}-\cos \theta_{a}\right)
$$

where $\theta_{a}$ is the advancing contact angle (here is $115.32^{\circ}$ ), $\theta_{r}$ is the receding contact angle (here is $91.6^{\circ}$ ), $\gamma_{l g}$ represents the liquid-gas surface tension. Thus, it is obvious that a stronger lateral resistance requires higher $\gamma_{l g}, \theta_{r}$ and $\theta_{a}$. The three factors are determined by the surface wettability, hence the lateral resistance force is highly dependent on the surface wettability.

According to the observation, as the bubbles grew bigger and bigger with the continuous injection of generated $\mathrm{H}_{2}$ molecules, there was bubble deformation owing to the asymmetric wettability, inducing the difference of Laplace pressure $(\Delta P)$. Furthermore, the difference of Laplace pressure provided the driving force for unidirectional gas transportation, which was mainly balanced by the lateral resistance $(f)$ of TPCL on the catalyst side. According to Equation 1, the lateral resistance can be accounted by the difference between advancing angle and intrinsic angle $(\Delta \theta)$, and the characteristic of cosine function determines that the maximum difference appears at the degrees near $90^{\circ}$ (high angle pinning state). Hence, based on such a strong lateral resistance, the obtained pressure difference of the deformed bubbles in a single tunnel can be calculated as,

$$
\Delta P=\frac{2 \gamma}{r}
$$

where $\gamma$ is the surface tension of the electrolyte, $r$ is the radius of curvature of the bubble cap on the catalyst side, which is basically determined by the wettability of the AO side and pore size of the mesh. Here, $\gamma$ is $0.072 \mathrm{~N} / \mathrm{m}, r$ is about $25 \mu \mathrm{m}$ according to the observation (Figure 4a), and critical $\triangle P$ in the single tunnel was calculated to reach up to $5760 \mathrm{~Pa}$. As supported by the calculation, the resistance of $\mathrm{Pt} / \mathrm{C}$ was calculated to be near $10.5 \mathrm{mN} / \mathrm{cm}$, much higher than other three surfaces studied. When the surface was at over-aerophobic state (sputtered Pt, Pt island and Pt flower array), the as-formed small bubbles on the catalyst side cannot be pinned and fused to a bigger bubble cap, thus the bubbles cannot be guided unidirectionally through the pores but release quickly on the catalyst side (Figure $4 \mathrm{~b}$ ). Only with sticky state, the fused and pinned bubble cap can provide such an ideal value of $\Delta P$ to overcome the hydrodynamic repulsion and release unidirectionally (Figure 4c).

We further assembled a device to verify the pressure resistance of the Janus membrane electrode under HER condition, as illustrated in an "H-type" electrolytic cell (Figure 4d). The Janus electrode with surface area of $2.29 \mathrm{~cm}^{2}$ and pore size of 50 
$\mu \mathrm{m}$ was placed in the middle of the "H-type" electrolytic cell as the working electrode, with catalyst side (AO side) facing the left half-cell. The left side half-cell was loaded with $\mathrm{H}_{2} \mathrm{SO}_{4}$ electrolyte, a carbon rod counter electrode and an $\mathrm{Ag} / \mathrm{AgCl}$ reference electrode. The right-side half-cell was loaded with small amount of colored water to test the pressure generated by unidirectional bubble transportation from the left cell to the right. Under a constant current of $30 \mathrm{~mA}$, the right pool was pressurized as indicated by a higher height of water column. The pressure of the right half-cell before the first small bubble formed on the AO side (i.e., the left cell) was recorded as the height difference between the two half-cells $(h)$, which reached up to $26.5 \mathrm{~cm}$ (as equal to $\sim 2600 \mathrm{~Pa}$ ). At the meantime, the Janus electrode was still pressurizing the as-generated gas into the right cell under such high pressure, indicating the considerable unidirectional gas transportation property. We further physically pressurized the right pool to test the resistance limit of the Janus membrane, a hydrostatic pressure of $58.3 \mathrm{~cm}$ water column (as equal to $\sim 5710 \mathrm{~Pa}$ ) was recorded before the first bubble crossed from the right half-cell to the left half-cell. The pressure was very close to the theoretical $\Delta P$, suggesting the resistance limit was the difference of Laplace pressure. In consequence, to acquire an adequate resistance to guarantee the sticky state, an appropriate tuning of wettability is critical. It is noteworthy that the value of $\Delta P$ in a single tunnel is determined by the pore size and wettability, the resistance limit and unidirectional gas transportation ability can be tuned to adapt various applications.

\section{Conclusion}

In conclusion, we have designed and demonstrated a porous stainless-steel mesh based Janus electrode with asymmetric wettability, employing superhydrophobic polytetrafluoroethylene (PTFE) thin layer coated on one side, and commercial $\mathrm{Pt} / \mathrm{C}$ (for HER, or Ir/C for OER) catalyst with well-balanced hydrophobicity coated on the other side, respectively. Floating the Janus electrode over the electrolyte with aerophilic PTFE side upward and aerophobic Pt/C catalyst side downward, the generated hydrogen gas from water splitting can be effectively transported through the tunnels within the electrode with no bubble adhesion on the catalyst side, realizing bubble-free and anti-buoyancy electrolysis with 15-folds higher current density obtained as compared with conventional electrodes. Due to the ideal lateral resistance of bubble and steady pinning of three-phase contact line (TPCL) as sticky state, $\mathrm{Pt} / \mathrm{C}$ (for HER cathode) or Ir/C (for OER anode) based Janus electrode exhibits superior gas transportation in electrocatalytic water splitting processes. This wettability modification strategy can generally enhance the mass transfer performances in various gas evolution reactions.

\section{Author Contributions}

Siyu Sheng, Liang Luo and Xiaoming Sun conceived the project. Siyu Sheng performed the experiments. Siyu Sheng, Liang Luo and Xiaoming Sun wrote the manuscript; Pengsong Li and Yun Kuang assisted the electro-catalytic tests. Cheng Wang, Bairu Shi and Fanhong Chen assisted the theoretical analysis; Zhicheng Shang 
assisted the illustrations. Xiao Lin, Hong Meng and Wenfeng Lin assisted in revising the manuscript. Xiaoming Sun and Liang Luo co-supervised the project. All authors have given approval to the final version of the manuscript.

\section{Funding Sources}

National Key Research and Development Project (No. 2018YFB1502401, 2018YFA0702002), Royal Society and the Newton Fund through the Newton Advanced Fellowship award (NAF $\backslash$ R1 $\backslash 191294)$, Program for Changjiang Scholars and Innovation Research Team in the University (No. IRT1205)

\section{Acknowledgments}

This work was supported by the National Natural Science Foundation of China (NSFC), the National Key Research and Development Project (No. 2018YFB1502401, 2018YFA0702002), the Royal Society and the Newton Fund through the Newton Advanced Fellowship award (NAF\R1\191294), the Program for Changjiang Scholars and Innovation Research Team in the University (No. IRT1205), the Fundamental Research Funds for the Central Universities, and the long-term subsidy mechanism from the Ministry of Finance and the Ministry of Education of PRC.

\section{Supporting Information}

Supporting Information is available from the authors.

Current density comparision of various PTFE coated Janus electrodes; contact angels, adhesion force measurements, polarization curves and digital camera images for Janus electrode; Janus electrode with Ir/C catalyst for OER test. (PDF)

\section{References:}

(1) Li, Y.; Gong, M.; Liang, Y.; Feng, J.; Kim, J. E.; Wang, H.; Hong, G.; Zhang, B.;

Dai, H. Advanced Zinc-Air Batteries Based on High-Performance Hybrid Electrocatalysts. Nat. Commun. 2013, 4, 1805.

(2) Suntivich, J.; Gasteiger, H. A.; Yabuuchi, N.; Nakanishi, H.; Goodenough, J. B.; Shao-Horn, Y. Design Principles for Oxygen-Reduction Activity on Perovskite Oxide Catalysts for Fuel Cells and Metal-Air Batteries. Nat. Chem. 2011, 3, 546-550.

(3) Li, P.; Wang, M.; Duan, X.; Zheng, L.; Cheng, X.; Zhang, Y.; Kuang, Y.; Li, Y.; Ma, Q.; Feng, Z.; Liu, W.; Sun, X. Boosting Oxygen Evolution of Single-Atomic 
Ruthenium through Electronic Coupling With Cobalt-Iron Layered Double Hydroxides. Nat. Commun. 2019, 10, 1711.

(4) Jiao, Y.; Zheng, Y.; Jaroniec, M.; Qiao, S. Z. Design of Electrocatalysts for Oxygen- and Hydrogen-Involving Energy Conversion Reactions. Chem. Soc. Rev. 2015, 44 , 2060-2086.

(5) Kibsgaard, J.; Chen, Z.; Reinecke, B. N.; Jaramillo, T. F. Engineering the Surface Structure of $\mathrm{MoS}_{2}$ to Preferentially Expose Active Edge Sites for Electrocatalysis. Nat. Mater. 2012, 11, 963-969.

(6) Wu, D.; Wei, Y.; Ren, X.; Ji, X.; Liu, Y.; Guo X.; Liu, Z.; Asiri, A.; Wei, Q.; Sun, X. $\quad \mathrm{Co}(\mathrm{OH})_{2}$ Nanoparticle-Encapsulating Conductive Nanowires Array: Room-Temperature Electrochemical Preparation for High-Performance Water Oxidation Electrocatalysis. Adv. Mater. 2018, 30, 1705366.1-1705366.7.

(7) Liu, T.; Liu, D.; Qu, F.; Wang, D.; Zhang, L.; Ge, R.; Hao, S.; Ma, Y.; Du, G.; Asiri, A.; Chen, L.; Sun, X. Enhanced Electrocatalysis for Energy-Efficient Hydrogen Production over CoP Catalyst with Nonelectroactive Zn as a Promoter. Adv. Energy Mater. 2017, 7, 1700020-1700027.

(8) Wang, W.; Yang, L.; Qu, F.; Liu, Z.; DU, G.; Asiri, A.; Yao, Y.; Chen, L,; Sun, X. A Self-Supported NiMoS4 Nanoarray as an Efficient 3D Cathode for the Alkaline Hydrogen Evolution Reaction. J.Mater.Chem.A 2017, 5, 16585-16589.

(9) Wang, T.; Zhang, X.; Zhu, X.; Liu, Q.; Lu, S.; Asiri, A.; Luo, Y.; Sun, X. Hierarchical CuO@ZnCo LDH Heterostructured Nanowire Array toward Enhanced Water Oxidation Electrocatalysis. Nanoscale 2020, 12, 5359-5362. 
(10) Kanan, M. W.; Nocera, D. G. In Situ Formation of an Oxygen-Evolving Catalyst in Neutral Water Containing Phosphate and $\mathrm{Co}^{2+}$. Science 2008, 321, 1072-1075.

(11) Li, J.; Chen, G.; Zhu, Y.; Liang, Z.; Pei, A.; Wu, C.-L.; Wang, H.; Lee, H. R.; Liu, K.; Chu, S.; Cui, Y. Efficient Electrocatalytic $\mathrm{CO}_{2}$ Reduction on a Three-Phase Interface. Nat. Catal. 2018, 1, 592-600.

(12) Li, J.; Zhu, Y.; Chen, W.; Lu, Z.; Xu, J.; Pei, A.; Peng, Y.; Zheng, X.; Zhang, Z.; Chu, S.; Cui, Y. Breathing-Mimicking Electrocatalysis for Oxygen Evolution and Reduction. Joule 2019, 3, 557-569.

(13) Lu, Z.; Li, Y.; Lei, X.; Liu, J.; Sun, X. Nanoarray Based "Superaerophobic" Surfaces for Gas Evolution Reaction Electrodes. Mater. Horizons 2015, 2, 294-298.

(14) Lu, Z.; Zhu, W.; Yu, X.; Zhang, H.; Li, Y.; Sun, X.; Wang, X.; Wang, H.; Wang, J.; Luo, J.; Lei, X.; Jiang, L. Ultrahigh Hydrogen Evolution Performance of Under-Water "Superaerophobic" $\mathrm{MoS}_{2}$ Nanostructured Electrodes. Adv. Mater. 2014, $26,2683-2687$.

(15) Xu, W.; Lu, Z.; Sun, X.; Jiang, L.; Duan, X. Superwetting Electrodes for Gas-Involving Electrocatalysis. Acc. Chem. Res. 2018, 51, 1590-1598.

(16) Li, Y.; Zhang, H.; Xu, T.; Lu, Z.; Wu, X.; Wan, P.; Sun, X.; Jiang, L. Under-Water Superaerophobic Pine-Shaped Pt Nanoarray Electrode for Ultrahigh-Performance Hydrogen Evolution. Adv. Funct. Mater. 2015, 25, 1737-1744.

(17) Stephani, K. A.; Goldstein, D. B. An Examination of Trapped Bubbles for Viscous Drag Reduction on Submerged Surfaces. J. Fluids Eng. 2010,132, 041303. 
(18) Brinkert, K.; Richter, M. H.; Akay, O.; Liedtke, J.; Giersig, M.; Fountaine, K. T.; Lewerenz, H. J. Efficient Solar Hydrogen Generation in Microgravity Environment. Nat. Commun. 2018, 9, 2527.

(19) Zhang, M.; Wang, L.; Hou, Y.; Shi, W.; Feng, S.; Zheng, Y. Controlled Smart Anisotropic Unidirectional Spreading of Droplet on a Fibrous Surface. Adv. Mater. 2015, 27, 5057-50623.

(20) Pei, C.; Peng, Y.; Zhang, Y.; Tian, D.; Liu, K.; Jiang, L. An Integrated Janus Mesh: Underwater Bubble Antibuoyancy Unidirectional Penetration. ACS Nano 2018, $12,5489-5494$.

(21) Wang, Z.; Li, Y.; Li, S.; Guo, J.; Zhang, S. Janus Porous Membrane with Conical Nanoneedle Channel for Rapid Unidirectional Water Transport. Chem. Commun (Camb) 2018, 54, 10954-10957.

(22) Wu, J.; Wang, N.; Wang, L.; Dong, H.; Zhao, Y.; Jiang, L. Unidirectional Water-Penetration Composite Fibrous Film via Electrospinning. Soft Matter. 2012, 8, 5996-5999.

(23) Zhu, S.; Li, J.; Cai, S.; Bian, Y.; Chen, C.; Xu, B.; Su, Y.; Hu, Y.; Wu, D.; Chu, J. Unidirectional Transport and Effective Collection of Underwater $\mathrm{CO}_{2}$ Bubbles Utilizing Ultrafast-Laser-Ablated Janus Foam. ACS Appl. Mater. Interfaces DOI: 10.1021/acsami.0c00464

(24) Yan, S.; Ren, F.; Li, C.; Jiao, Y.; Wang, C.; Wu, S.; Wei, S.; Hu, Y.; Li, J.; Xiao, Y.; Su, Y.; Wu, D. Unidirectional Self-Transport of Air Bubble via a Janus Membrane in Aqueous Environment. Appl. Phys. Lett. 2018, 113, 261602-261606. 
(25) Hu, Y.; Qiu, W.; Zhang, Y.; Zhang, Y.; Li, C.; Li, J.; Wu, S.; Zhu, W.; Wu, D.;

Chu, J. Channel-Controlled Janus Membrane Fabricated by Simultaneous Laser Ablation and Nanoparticles Deposition for Underwater Bubbles Manipulation. Appl. Phys. Lett. 2019, 114, 173701-173705.

(26) Cao, M.; Xiao, J.; Yu, C.; Li, K.; Jiang, L. Hydrophobic/Hydrophilic Cooperative Janus System for Enhancement of Fog Collection. Small 2015, 11, 4379-4384.

(27) Wu, M. B.; Yang, H. C.; Wang, J. J.; Wu, G. P.; Xu, Z. K. Janus Membranes with Opposing Surface Wettability Enabling Oil-to-Water and Water-to-Oil Emulsification. ACS Appl. Mater. Interfaces 2017, 9, 5062-5066.

(28) Tian, X.; Jin, H.; Sainio, J.; Ras, R. H. A.; Ikkala, O. Droplet and Fluid Gating by Biomimetic Janus Membranes. Adv. Funct. Mater. 2014, 24, 6023-6028.

(29) Ma, Q.; Cheng, H.; Fane, A. G.; Wang, R.; Zhang, H. Recent Development of Advanced Materials with Special Wettability for Selective Oil/Water Separation. Small 2016, 12, 2186-2202.

(30) Mi, L.; Yu, J.; He, F.; Jiang, L.; Wu, Y.; Yang, L.; Han, X.; Li, Y.; Liu, A.; Wei, W.; Zhang, Y.; Tian, Y.; Liu, S.; Jiang, L. Boosting Gas Involved Reactions at Nanochannel Reactor with Joint Gas-Solid-Liquid Interfaces and Controlled Wettability. J. Am. Chem. Soc. 2017, 139, 10441-10446.

(31) Sheng, X.; Liu, Z.; Zeng, R.; Chen, L.; Feng, X.; Jiang, L. Enhanced Photocatalytic Reaction at Air-Liquid-Solid Joint Interfaces. J. Am. Chem. Soc. 2017, $139,12402-12405$.

(32) Gao, S.; Mohammad, M.; Yang, H. C.; Xu, J.; Liang, K.; Hou, J.; Chen, V. Janus 
Reactors with Highly Efficient Enzymatic $\mathrm{CO}_{2}$ Nanocascade at Air-Liquid Interface. ACS Appl. Mater. Interfaces 2017, 9, 42806-42815.

(33) Yang, H. C.; Hou, J.; Chen, V.; Xu, Z. K. Janus Membranes: Exploring Duality for Advanced Separation. Angew Chem. Int .Ed. Engl. 2016, 55, 13398-13407.

(34) Ramiasa, M.; Ralston, J.; Fetzer, R.; Sedev, R.; Fopp-Spori, D. M.; Morhard, C.; Pacholski, C.; Spatz, J. P. Contact Line Motion on Nanorough Surfaces: a Thermally Activated Process. J. Am. Chem. Soc. 2013, 135, 7159-7171.

(35) Tadmor, R.; Bahadur, P.; Leh, A.; N'Guessan H, E.; Jaini, R.; Dang, L. Measurement of Lateral Adhesion Forces at the Interface Between a Liquid Drop and a Substrate. Phys. Rev. Lett. 2009, 103, 266101.

(36) Gao, N.; Geyer, F.; Pilat, D. W.; Wooh, S.; Vollmer, D.; Butt, H.-J.; Berger, R. How Drops Start Sliding Over Solid Surfaces. Nat. Phys. 2017, 14, 191-196.

(37) T. Young, An Essay on the Cohesion of Fluids. Philos. Trans. R. Soc. London $\mathbf{1 8 0 5}, 95,65-87$.

(38) Qiao, S.; Li, S.; Li, Q.; Li, B.; Liu, K.; Feng, X. Friction of Droplets Sliding on Microstructured Superhydrophobic Surfaces. Langmuir 2017, 33, 13480-13489. 


\section{TOC graphic}
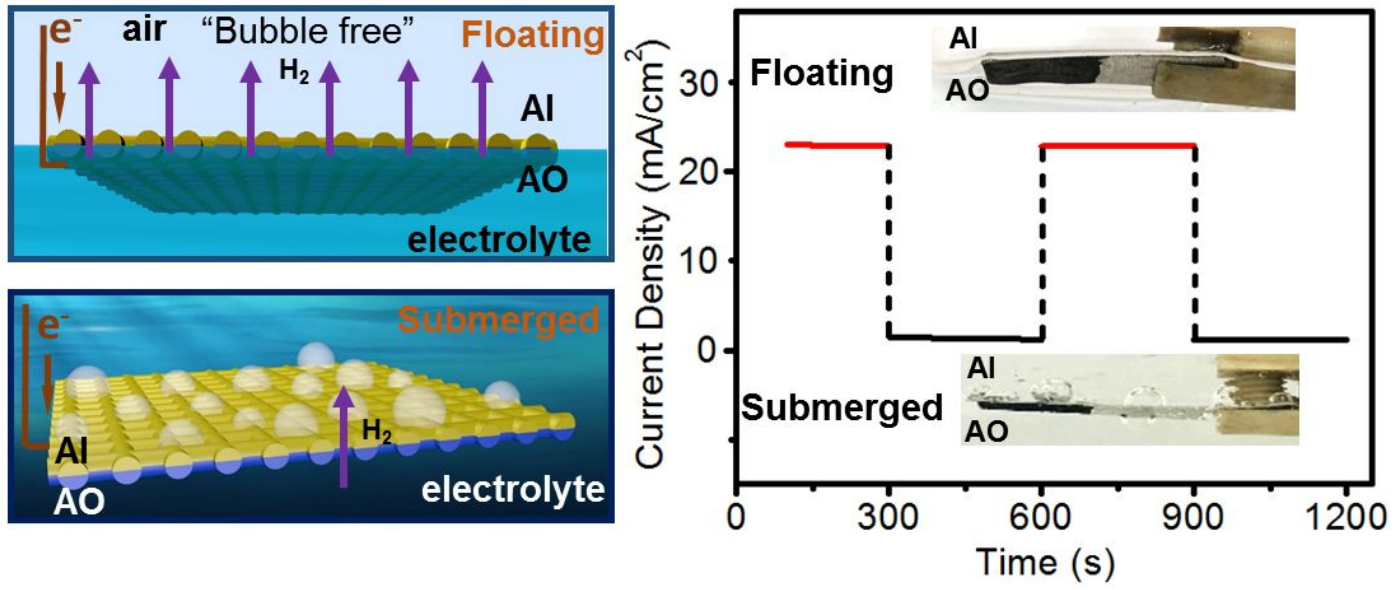


\section{Figures and their captions}

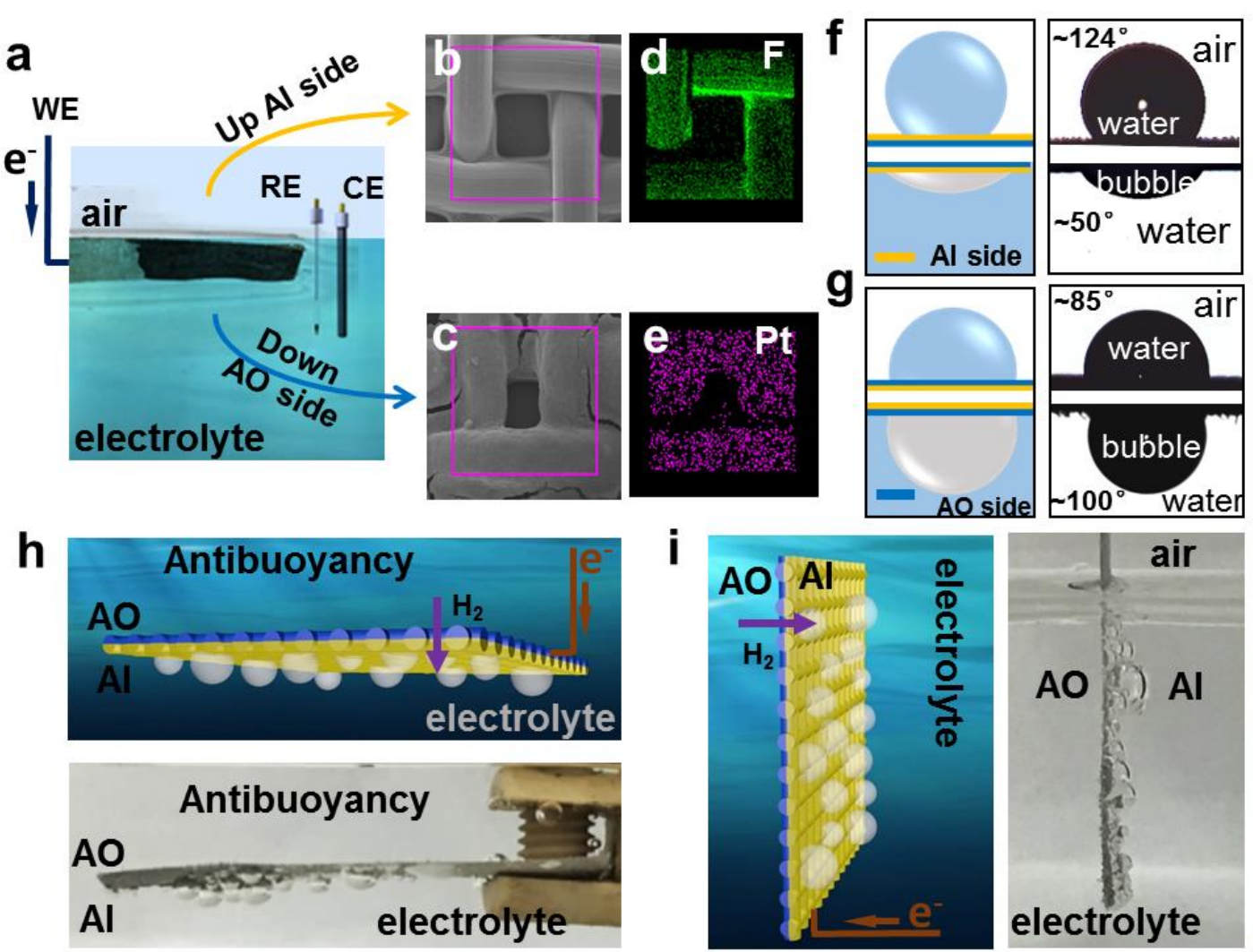

Figure 1. (a) Digital camera image of Janus electrode floating over the electrolyte with the aerophilic (AI) side upward and aerophobic (AO) side downward during hydrogen evolution reaction. WE: Janus mesh electrode, CE: carbon rod, RE: $\mathrm{Ag} / \mathrm{AgCl}$ electrode. SEM images of (b) aerophilic and (c) aerophobic side and elemental mapping images of (d) F and (e) Pt. (f, g) Digital camera images showing 


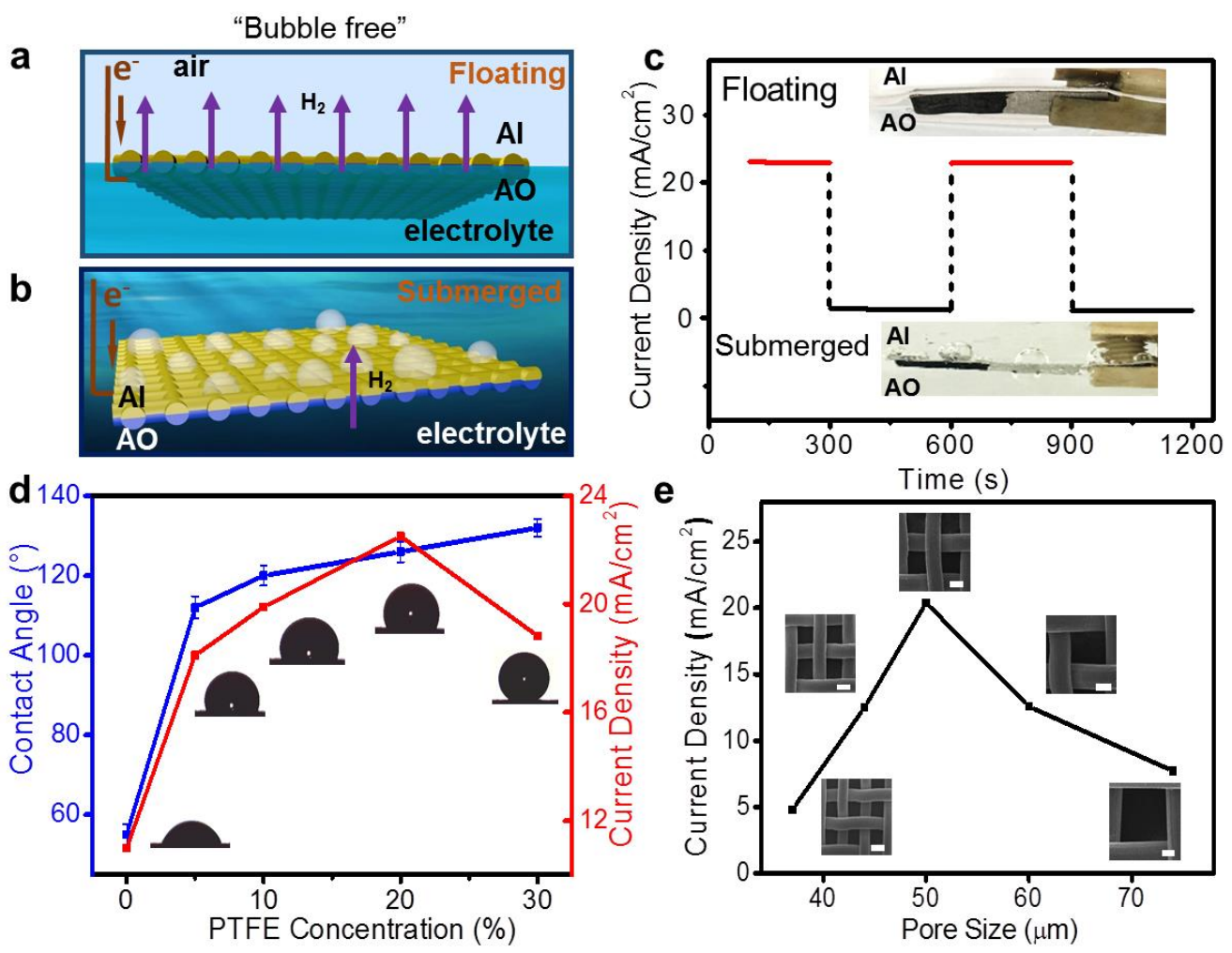

Figure 2. (a-b) Schematic illustration and (c) comparison of current densities for Janus electrode with floating or submerged states. (d) Different water contact angles and current densities of the AI side of Janus electrodes modified with different PTFE concentration. (e) Current densities of Janus electrodes with different pore sizes, scale bars are $20 \mu \mathrm{m}$. 

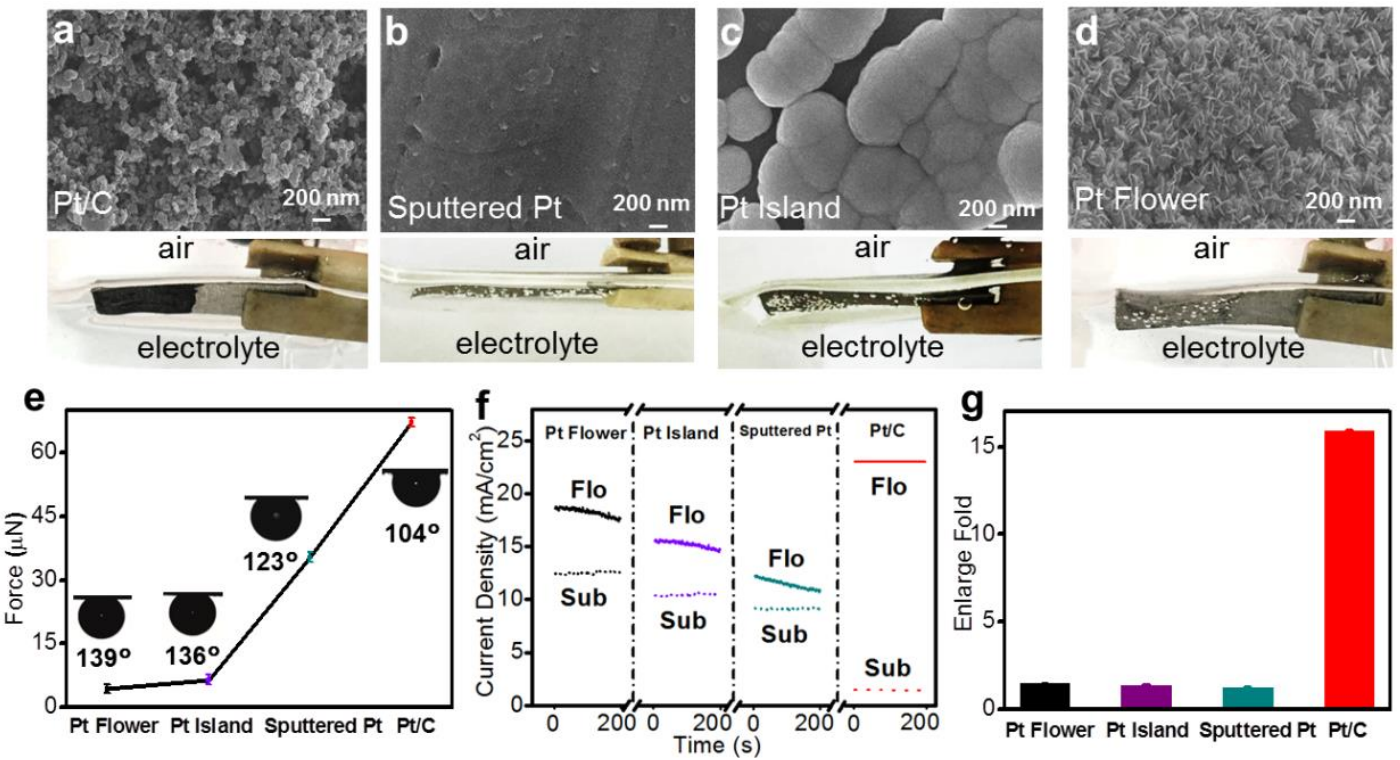

Figure 3. (a-d) SEM images and camera images of Janus electrode coated with four different catalysts: Pt/C nanoparticles, sputtered Pt film, Pt island and Pt flower array. (e) Adhesive force measurement on the above four catalysts with different bubble contact angles. (f) HER current densities obtained on different Pt catalysts at a constant potential of $-0.30 \mathrm{~V}$ vs RHE.(Flo: Floating state. Sub: Submerged state) (g) The current density enhancement factors on the four different catalyst surfaces. 


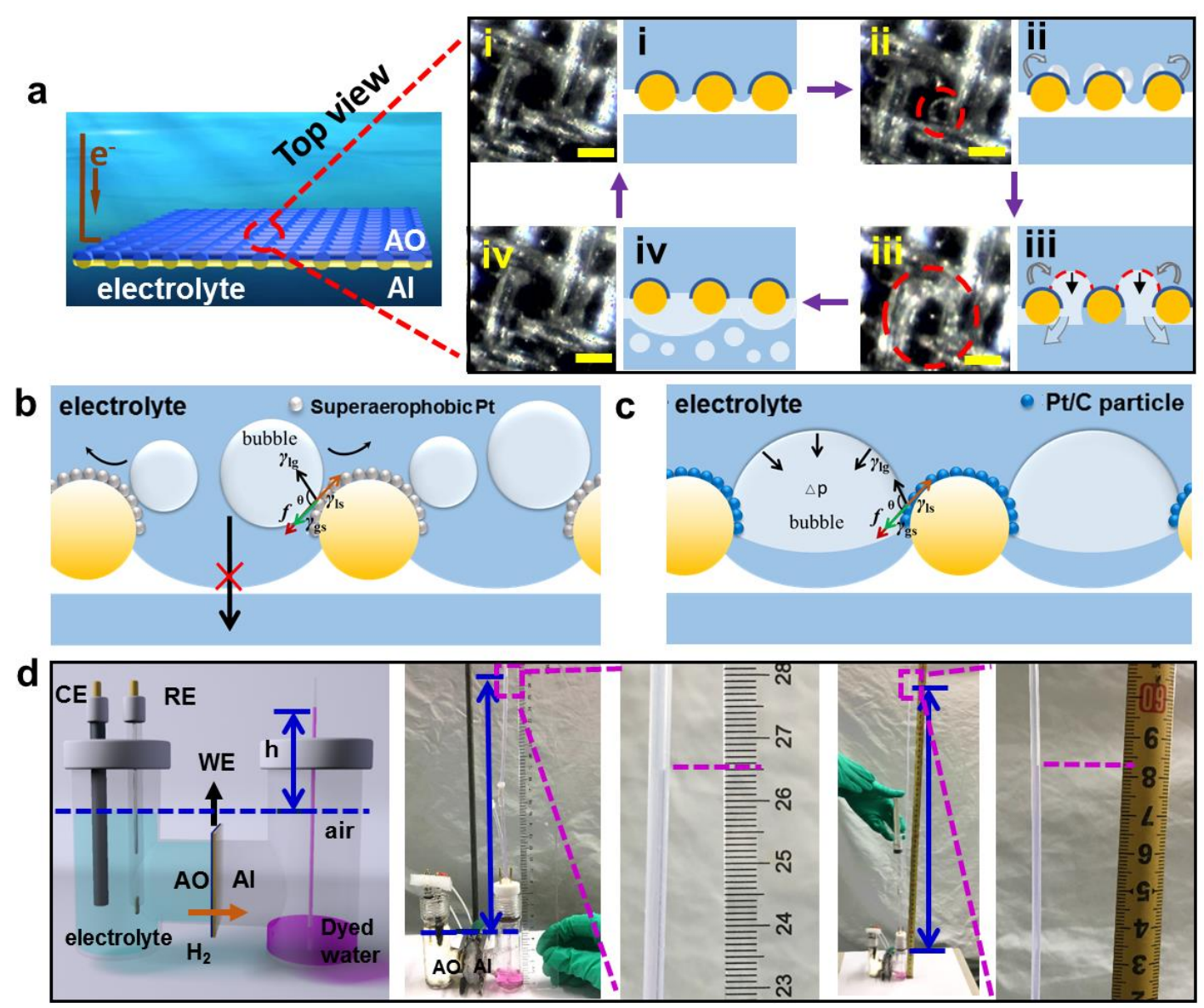

Figure 4. (a) Magnified snapshots and illustration of a bubble evolution cycle on the $\mathrm{Pt} / \mathrm{C}$ catalyst side (i.e., the AO side). Scale bars are $50 \mu \mathrm{m}$. Analysis of bubble transportation on (b) plain aerophobic surface and (c) sticky aerophobic surface. (d) Measurement of generated vapor pressure based on the Janus electrode. 


\section{TOC graphic}
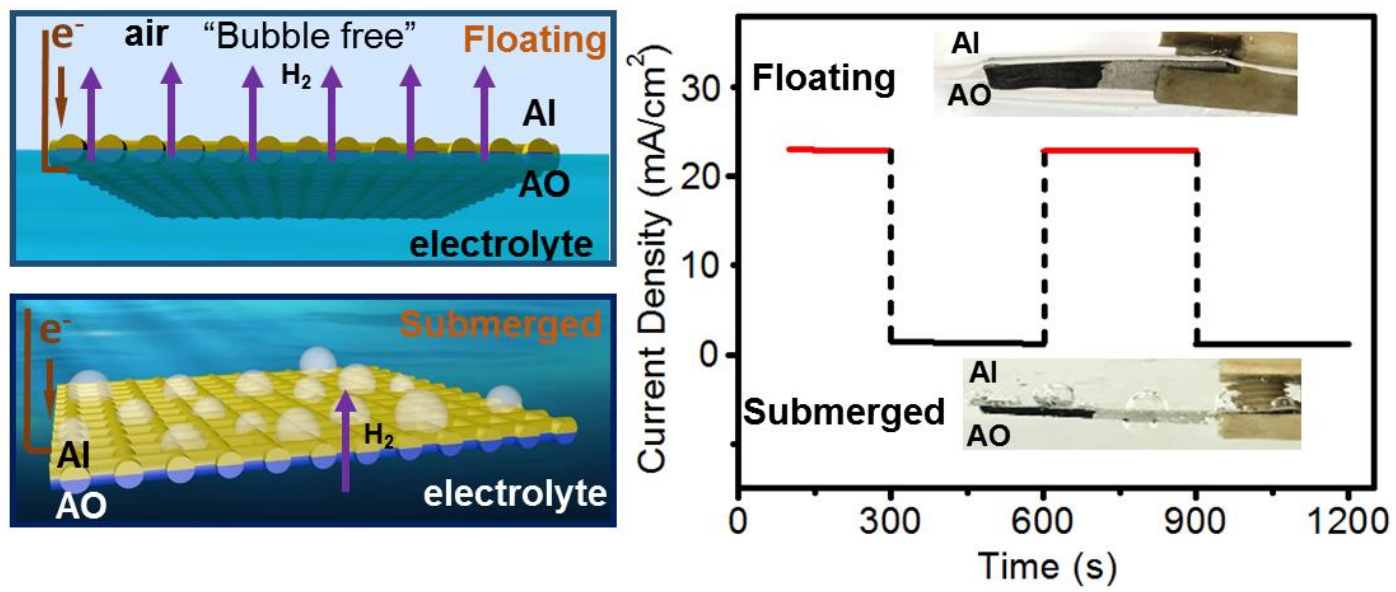